\title{
A MODEL OF RISK FOR ASSESSMENT OF SAFETY OF SHIPS IN DAMAGED CONDITIONS
}

\section{MODEL RYZYKA DLA OCENY BEZPIECZEŃSTWA STATKÓW W STANIE USZKODZONYM}

\author{
Mirosław Gerigk \\ Gdańsk University of Technology \\ Politechnika Gdańska \\ 80-952 Gdańsk ul. G.Narutowicza 11/12 \\ e-mail: (1) mger@pg.gda.pl
}

\begin{abstract}
The paper regards modelling of hazards, consequences and risk for a method for assessment of safety of ships in damaged conditions. The method applies the performances-oriented approach and risk-based approach combined together within the method. The performance-oriented approach regards predicting the behavior of a ship in damaged conditions at sea. The risk-based approach is connected with applying the hazard identification, scenarios development, risk assessment and risk control. Safety is treated as an objective between the other design or operational objectives. The safety measure is risk regarding the losses.
\end{abstract}

Keywords: safety of ships, risk assessment, modelling of risk

Streszczenie: W artykule przedstawiono informacje na temat modelowania zagrożeń, konsekwencji i ryzyka wypadku w metodzie oceny bezpieczeństwa statków w stanie uszkodzonym. Metoda oparta jest na połączeniu podejścia opartego na ocenie zachowania się statku z podejściem opartym o ocenę ryzyka. Podejście oparte na ocenie zachowania się statku, dotyczy głównie określenia jego charakterystyk hydromechanicznych. Podejście oparte o ocenę ryzyka dotyczy identyfikacji zagrożeń i scenariuszy wypadku oraz oceny i kontroli tego ryzyka. Bezpieczeństwo jest celem projektowym (operacyjnym) a ryzyko jego miara.

Słowa kluczowe: bezpieczeństwo statków, ocena ryzyka, modelowanie ryzyka 


\section{MODEL OF RISK FOR ASSESSMENT OF SAFETY OF SHIPS IN DAMAGED CONDITIONS}

\section{Introduction}

The paper presents a few problems on modelling the hazards, consequences and risk for assessment of safety of ships in damaged conditions for safe operation. The research concerns development of a performance-oriented risk-based method for assessment of safety of ships. A kind of such a method should be the current method of assessment of safety of ships in damaged conditions based on the harmonized SOLAS Chapter II-1 [4][5]. The safety regulations included in SOLAS are prescriptive in their character. They are based on the probabilistic and semi-probabilistic approaches to safety but they do not take into account all the possible hazards and scenarios of accidents at sea. They are more devoted to the design aspects of safety. Application of the requirements included in these regulations to certain types of ships e.g. large passenger vessels, Ro-Ro vessels or car-carriers may lead to insufficient level of a ship safety and provide unnecessary design restrictions. IMO has decided to improve the prescriptive regulations and create the sets of new rules based on application of the risk assessment technology. For the whole process of improving the rules IMO has recommended to implement the Formal Safety Assessment FSA methodology published as MSC Circ. 1023 [2][3]. The new sets of rules should be directed towards satisfying the objectives. A good example of such the rules are the Goad-Based Standards [5].

\section{Current method of assessment of safety of ships in damaged conditions}

The current method for assessment of safety of ships in damaged conditions is based on the regulations included in the SOLAS Chapter II-I. Using this method the measure of safety of a ship in damaged conditions is the attained subdivision index A. It is treated as the probability of survival of flooding any group of compartments. The basic design criteria is the condition as follows [4][5]: 
where A - attained subdivision index calculated, for the ship draughts $d_{s}, d_{p}$ and $\mathrm{d}_{1}$ defined in regulation 2 , according to the formula [4]:

$\mathrm{A}=\sum \mathrm{p}_{\mathrm{i}} \mathrm{s}_{\mathrm{i}}$

where $p_{i}$ - probability that only the compartment or group of compartments under consideration may be flooded, as defined in regulation 7-1 [4]; $\mathrm{s}_{\mathrm{i}}$ probability of survival after flooding the compartment or group of compartments under consideration, as defined in regulation 7-2 [4]; $\mathrm{R}$ required subdivision index.

The probabilities $p_{i}$ and $s_{i}$ are calculated according to the well known formulae accepted by IMO [4][5]. A typical process of assessment of safety of ships in damaged conditions at the design stage or when the survivability of existing ships is considered is connected with satisfying the criteria (1). Even if the criteria (1) is satisfied there are some doubts if a ship could really be safe in operation. Of course, the optimisation of the attained subdivision index A can be applied to increase the ship safety. The optimisation may concern optimisation of the so-called local safety indices as well. However these techniques should be considered as prescriptive as the method itself. The preliminary calculations associated with using these techniques were conducted at the University of Newcastle upon Tyne in 1991 by Gerigk [8]. The investigations which have been performed after that confirmed the disadvantages connected with application of the current method [1].

\section{Performance-oriented risk-based method}

As it was introduced by Vassalos and the others the risk-based design is a formalized design methodology that integrates the risk analysis in the design process with the prevention/reduction of risk embedded as a design objective, along standard design objectives. This methodology applies a holistic approach that links the risk prevention/reduction measures to ship performance and cost by using relevant tools to address ship design and operation [9][10][11]. The approach for assessment of safety of ships for design, safe operation and salvage applied for the method is based on the following steps: setting the objectives, hazard identification, scenarios development, risk assessment, risk control (prevention, reduction), selection 
of designs (operational procedures) that meet the objectives. The original structure of the method and proposed risk-based design system for assessment of safety of ships in damaged conditions is presented in Fig. 1.

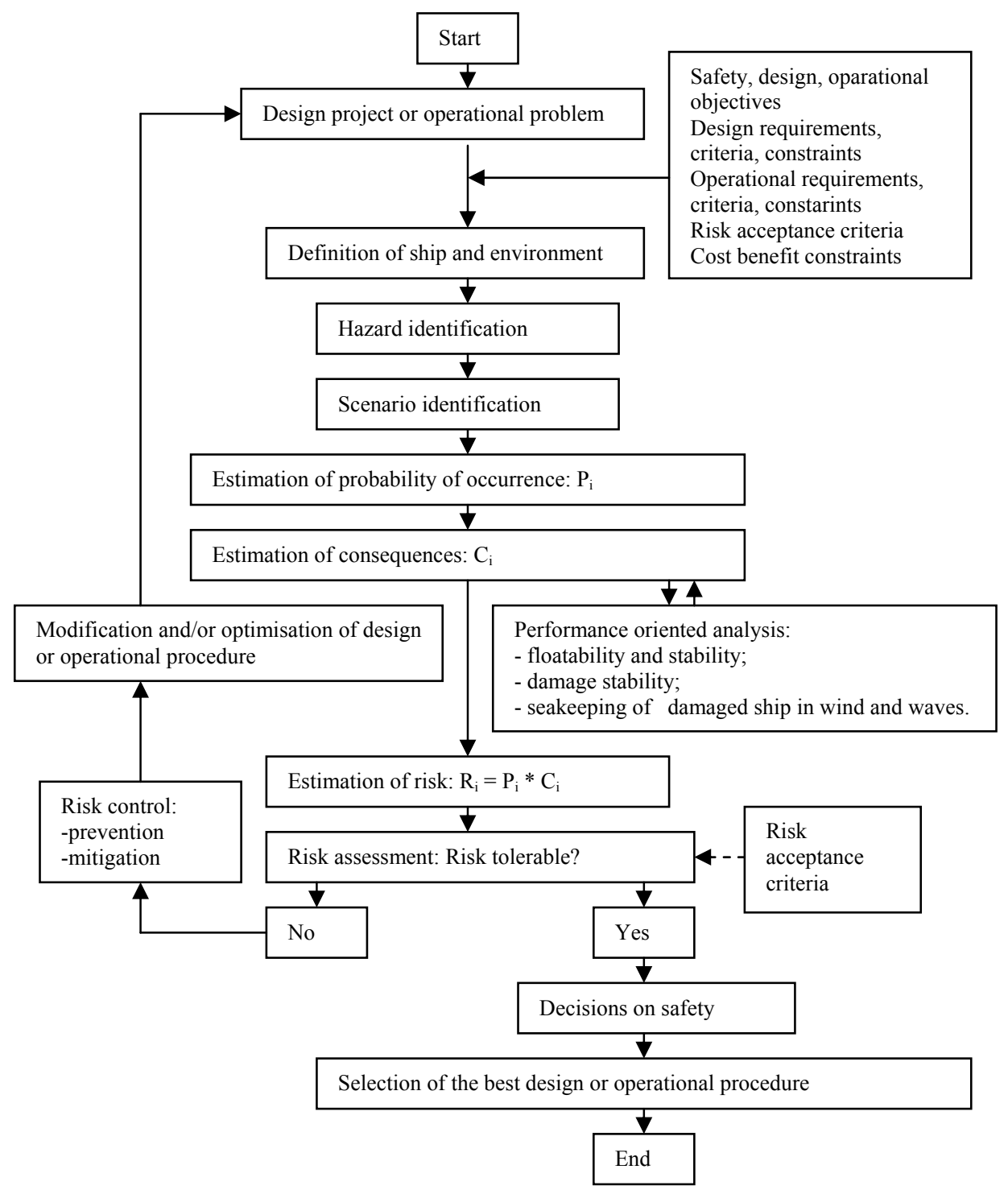

Fig. 1 Logical structure of the risk-based design system (method)

The proposed method is a kind of performance-oriented risk-based procedure which can be used for the design for safety or safe operation 
including the reduction of risk and delivering the sufficient level of safety as an objective. Generally, the method can be used for assessment of safety of either the undamaged or damaged ships as it depends on the system (problem) definition.

The modern approach to ship safety is connected with combining the elements of system approach to safety and Formal Safety Assessment (FSA) methodology [2][3]. The major elements of the FSA methodology are as follows: hazard identification, risk analysis, risk control options, costbenefit assessment, recommendations for decision making. The above steps have been combined with the modern ship design spiral [1]. The following methods have been used for the risk assessment including the hazard identification methods, frequency assessment methods, consequence assessment methods and risk evaluation methods [1]: preliminary hazard analysis (PHA), preliminary risk analysis (PRA), what-if/checklist analysis, failure modes and effects analysis (FMEA), hazard and operability analysis (HAZOP), fault tree analysis (FTA), event tree analysis (ETA), relative ranking, coarse risk analysis (CRA), pareto analysis, change analysis, common cause failure analysis (CCFA) and human error analysis (HEA).

\section{Modelling hazards, consequences and risk}

The key issue when using the proposed method is to model the risk contribution tree for the risk assessment. Three categories of accidents which may potentially cause a damage to the ship were taken into account: collision, stranding and grounding. According to the statistics these categories are the main reasons of accidents at sea. They constitute about $53 \%$ of the whole number of accidents [6]. The risk contribution trees for the collision, stranding and grounding were developed separately according to the general fault tree FTA and event tree ETA structures. The functional event tree approach has been applied for the method. The functional event tree may have a dynamical character. The set of sixteen safety functions have been introduced for the method.

The holistic approach to ship safety has been applied. According to this approach two major assumptions have been done. First that the system failures can be either the hardware, software, organizational or human failures. The second assumption concerns the holistic risk model to be applied for assessment of safety of ships in damaged conditions.

The risk associated with the different hazards and scenario development was estimated according to the well known general formulae: 
$\mathrm{R}_{\mathrm{i}}=\mathrm{P}_{\mathrm{i}} \times \mathrm{C}_{\mathrm{i}}$

where $\mathrm{P}_{\mathrm{i}}$ - probability of occurrence of a given hazard; $\mathrm{C}_{\mathrm{i}}$-consequences following the occurrence of the data hazard and scenario development, in terms of fatalities, injuries, property losses and damage to the environment. The holistic risk model for the assessment of safety of ships in damaged conditions is as follows [1][7][9]:

$\mathrm{R}=\mathrm{P}_{\mathrm{c}} \times \mathrm{P}_{\mathrm{c} / \text { fdpe }} \times \mathrm{P}_{\mathrm{c} / \text { fdpe/ns }} \times \mathrm{P}_{\mathrm{c} / \text { fdpe/ns/tts }} \times \mathrm{C}$

where $\mathrm{P}_{\mathrm{c}}$ - probability of collision (hazard); $\mathrm{P}_{\mathrm{c} / \mathrm{fdpe}}$ - probability of flooding having the ship hit from given direction at data position with given extent conditional on collision; $\mathrm{P}_{\mathrm{c} / \mathrm{fdpe} / \mathrm{ns}}$ - probability of not surviving conditional on having flooding when the ship is hit from given direction at data position with given extent conditional on collision; $\mathrm{P}_{\mathrm{c} / \mathrm{fdpe} / \mathrm{ns} / \mathrm{ts}}$ - probability of given time to sink conditional on not surviving the conditional on having flooding when the ship is hit from given direction at data position with given extent conditional on collision; $\mathrm{C}$ - consequences regarding the fatalities, property (cargo, ship) and/or environment.

The risk model may be divided into four different modules depending on the losses regarding the human fatalities (HF), cargo and ship losses (CS), environment pollution (E) and financial losses (\$) as follows:

$\mathrm{R}=\mathrm{P}_{\mathrm{c}} \mathrm{P}_{\mathrm{c} / \text { fdpe }} \mathrm{P}_{\mathrm{c} / \mathrm{fdpe} / \mathrm{ns}} \mathrm{P}_{\mathrm{c} / \mathrm{fdpe} / \mathrm{ns} / \mathrm{ts}} \times \mathrm{C}_{\mathrm{HF} / \mathrm{C}}$

$\mathrm{R}=\mathrm{P}_{\mathrm{c}} \mathrm{P}_{\mathrm{c} / \text { fdpe }} \mathrm{P}_{\mathrm{c} / \text { fdpe/ns }} \mathrm{P}_{\mathrm{c} / \text { fdpe/ns/tts }} \times \mathrm{C}_{\mathrm{CS} / \mathrm{C}}$

$\mathrm{R}=\mathrm{P}_{\mathrm{c}} \mathrm{P}_{\mathrm{c} / \mathrm{fdpe}} \mathrm{P}_{\mathrm{c} / \text { fdpe/ns }} \mathrm{P}_{\mathrm{c} / \text { fdpe/ns/tss }} \times \mathrm{C}_{\mathrm{E} / \mathrm{C}}$

$\mathrm{R}=\mathrm{P}_{\mathrm{c}} \mathrm{P}_{\mathrm{c} / \text { fdpe }} \mathrm{P}_{\mathrm{c} / \text { fdpe/ns }} \mathrm{P}_{\mathrm{c} / \text { /dpe/ns/tts }} \times \mathrm{C}_{\$ / \mathrm{C}}$

The general formulae for estimation of the probability of occurring the given consequences, taking the data accident scenario into account, is as follows:

$\mathrm{PC}_{\mathrm{i}}=\sum_{N p r} \mathrm{P}\left(\mathrm{r}_{\mathrm{j}}\right) \mathrm{P}\left(\mathrm{C}_{\mathrm{i}}, \mathrm{r}_{\mathrm{j}}\right)$

where $\mathrm{Npr}$ - number of possible events for the given accident scenario; $\mathrm{P}\left(\mathrm{r}_{\mathrm{j}}\right)$ - probability of occurrence of a given event; $\mathrm{P}\left(\mathrm{C}_{\mathrm{i}}, \mathrm{r}_{\mathrm{j}}\right)$ - probability of occurring the given consequences $\mathrm{C}_{\mathrm{i}}$ conditional on occurrence of the given set of events $r_{j}$.

The typical releases may be as follows: water on deck, air cushions, cargo leakage, additional heeling moments, passenger behavior.

The risk model (4) is different from the model presented by Skjong et al. [9] as it does not use the conditional probability of sinking given by the Psink 
=1-A complement probability of the attained subdivision index A [9]. An example a ship performance data (roll) and final results of the risk distribution $\left(\mathrm{R}_{\mathrm{i}}=\mathrm{P}_{\mathrm{i}} * \mathrm{C}_{\mathrm{i}}\right)$ in terms of surviving the collision are presented in Figure 2.
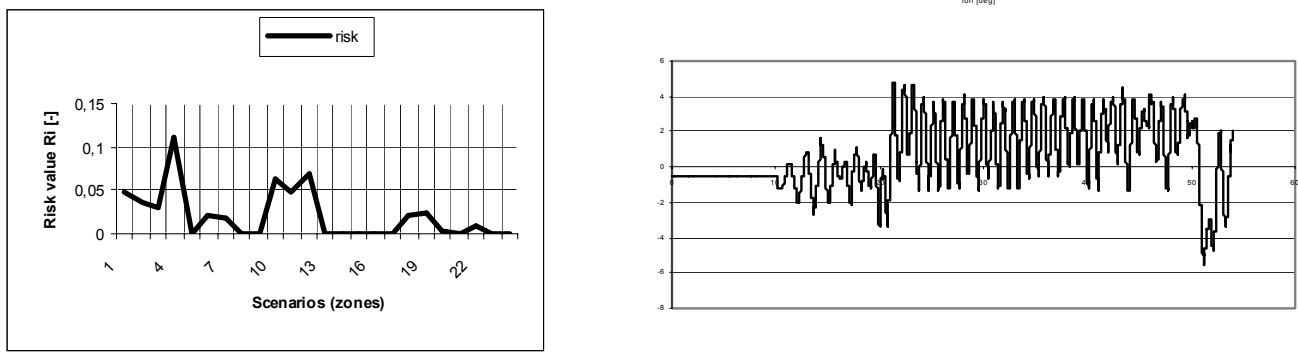

Figure. 2. An example a ship performance data (roll) and final results of the risk distribution $\left(\mathrm{R}_{\mathrm{i}}=\mathrm{P}_{\mathrm{i}} * \mathrm{C}_{\mathrm{i}}\right)$

\section{Conclusions}

The performance-oriented risk-based method for assessment of safety of ships in damaged conditions is very briefly presented in the paper. The current work regarding the method is associated with further developing the performance-oriented and risk-based models. Then the models are being implemented as the safety procedures during the investigations on safety of ships based on either the model tests or numerical simulation. The method suppose to be implemented for the design, operational and salvage-oriented purposes.

\section{Acknowledgements}

The author would like to express his kind gratitude to the Ministry of Science and High Education, for the support to carry out the investigations on novel solutions for assessment of safety of ships. 


\section{References}

1. Gerigk, M. 2006. A method for assessing hazards, risks and safety of damaged ships at sea, BALKEMA - Proceedings and Monographs in Engineering, Water and Earth Sciences. Proceedings of the European Safety and Reliability Conference 2006 (ESREL 2006), Volume 3, Estoril, Portugal, 18-22 September 2006, Published by Taylor \& Francis / Balkema, London / Leiden / New York / Philadelphia / Singapore.

2. IMO. 1997. Interim guidelines for the application of formal safety assessment (FSA) to the IMO rule - making process, MSC/Circ.829, MEPC/Circ.335, London, 17 November 1997.

3. IMO. 2002a. Guidelines for formal safety assessment (FSA) for use in the IMO rule-making process, MSC/Circ.1023, MEPC/Circ.392, London, 5 April 2002.

4. IMO. 2005. Report of the Maritime Safety Committee on Its Eightieth Session, MSC 80/24/Add.1, London, 2005.

5. IMO. 2008. http://www.imo.org.

6. Kobylinski L. 2001. Philosophy of safety at sea (in Polish), $1^{\text {st }}$ International Workshop "Safety at Sea", Gdansk University of Technology, Gdansk, August 2001.

7. Jasionowski, A. \& Vassalos, D. 2006. Coceptualising Risk, Proceedings of the $9^{\text {th }}$ International Conference on Stability of Ships and Ocean Vehicles, Rio de Janeiro, 25-29 September 2006.

8. Sen, P. \& Gerigk, M. 1992. Some Aspects of a Knowledge-Based Expert System for Preliminary Ship Subdivision Design for Safety, Proceedings of the $5^{\text {th }}$ International Symposium PRADS'92 on Practical Design of Ships and Mobile Units, Newcastle, May 1992, Edited by J.B.Caldwell and G.Ward, London, New York, Elsevier Applied Science, 1992.

9. Skjong R. \& Vanem E. \& Rusas S. \& Olufsen O. 2006. Holistic and Risk Based Approach to Collision Damage Stability of Passenger Ships, Proceedings of the $9^{\text {th }}$ International Conference on Stability of Ships and Ocean Vehicles, Rio de Janeiro, 25-29 September 2006.

10. SSRC. 2008. http://www.ssrc.na-me.ac.uk.

11. Vassalos, D. 2006. Passenger Ship Safety: Containing the Risk, Marine Technology, Vol. 43, No. 4, October 2006, pp. 203-213. 


\section{MODEL RYZYKA DLA OCENY BEZPIECZEŃSTWA STATKÓW W STANIE USZKODZONYM}

\section{Wprowadzenie}

$\mathrm{W}$ artykule przedstawiono wybrane problemy związane z modelowaniem zagrożeń, konsekwencji i ryzyka wypadku, dla oceny bezpieczeństwa statków w stanie uszkodzonym. Badania dotyczyły opracowania metody oceny bezpieczeństwa, opartej na ocenie zachowania się statku i ocenie ryzyka. Metodą taką powinna być obecna metoda oceny bezpieczeństwa statków W stanie uszkodzonym, zawarta W zharmonizowanej wersji konwencji SOLAS rozdział II-1 [4][5]. Jednak, przepisy bezpieczeństwa zawarte $\mathrm{w}$ tej konwencji maja charakter preskrypcyjny. Oparte są na zastosowaniu podejścia probabilistycznego i semi-probabilistycznego do bezpieczeństwa, lecz w przepisach tych nie uwzględniono wszystkich możliwych zagrożeń i scenariuszy wypadków na morzu. Przepisy te są ukierunkowane głównie na problemy związane z projektowaniem statków. Zastosowanie wymagań, zawartych $\mathrm{w}$ tych przepisach, w stosunku do pewnych typów statków, jak statki pasażerskie, statki typu Ro-Ro czy samochodowce, może prowadzić do niedostatecznego poziomu bezpieczeństwa lub do niepożądanych ograniczeń projektowych. Międzynarodowa Organizacja Morska IMO zdecydowała się na ulepszenie tych przepisów i opracowanie ich nowej wersji w oparciu o zastosowanie oceny ryzyka. Do ulepszania przepisów IMO zaproponowała zastosowanie metodologii Formalnej Oceny Bezpieczeństwa FSA, opublikowanej w formie dokumentu MSC Circ. 1023 [2][3]. Nowe przepisy powinny być ukierunkowane na osiągnięcie celów. Przykładem takich przepisów są „Standardy ukierunkowane na Osiagniecie Celów”, czyli tak zwane GoalBased Standards [5].

\section{Obecna metoda oceny bezpieczeństwa statków w stanie uszkodzonym}

Miarą bezpieczeństwa statku w stanie uszkodzonym w obecnej metodzie jest wskaźnik podziału grodziowego A. Wskaźnik A traktowany jest jako prawdopodobieństwo przetrwania zatopienia dowolnej grupy przedziałów wodoszczelnych statku. Podstawowym kryterium projektowym w metodzie jest następujący warunek [4][5]: 
gdzie A - wskaźnik podziału grodziowego, obliczany dla zanurzeń statku $\mathrm{d}_{\mathrm{s}}$, $\mathrm{d}_{\mathrm{p}}, \mathrm{d}_{1}$, zdefiniowanych $\mathrm{w}$,,regulation 2”, według wzoru [4]:

$\mathrm{A}=\sum \mathrm{p}_{\mathrm{i}} \mathrm{s}_{\mathrm{i}}$

gdzie $p_{i}$ - prawdopodobieństwo zatopienia rozważanego przedziału lub grupy przedziałów, zgodnie z definicją podaną w ,regulation 7-1” [4]; $\mathrm{s}_{\mathrm{i}}-$ prawdopodobieństwo warunkowe przetrwania zatopienia rozważanego przedziału lub grupy przedziałów, zgodnie $\mathrm{z}$ definicja podaną $\mathrm{w}$,,regulation 7-2" [4]; R - wymagany wskaźnik podziału grodziowego.

Prawdopodobieństwa $p_{i}$ i $s_{i}$ należy obliczać zgodnie $z$ wyrażeniami zaakceptowanymi przez IMO [4][5]. Typowy proces oceny bezpieczeństwa statków w stanie uszkodzonym, na etapie projektowania lub przy ocenie prawdopodobieństwa przetrwania kolizji, w przypadku statków istniejących, związany jest ze spełnieniem warunku (1). Nawet, jeśli warunek (1) jest spełniony mogą pojawić się wątpliwości czy statek będzie rzeczywiście bezpieczny w czasie eksploatacji. Oczywiście, można zadbać o podwyższenie bezpieczeństwa projektowanego statku poprzez optymalizację wskaźnika podziału grodziowego A. Optymalizacja może być też związana $\mathrm{z}$ obliczeniami tak zwanych lokalnych współczynników bezpieczeństwa. Jednak, powyższe metody optymalizacji mają także charakter preskrypcyjny. Pierwsze badania w tym zakresie zostały przeprowadzone przez autora na Uniwersytecie "Newcastle upon Tyne” w roku 1991 [8]. Kontynuowane, w kolejnych latach, prace badawcze potwierdziły wady związane z zastosowaniem obecnej metody.

\section{Metoda oparta na ocenie zachowania się statku i ocenie ryzyka}

Profesor Dracos Vassalos z „Ship Stability Research Centre” w Glasgow i inni specjaliści, zajmujący omawiana dziedziną wiedzy, określili projektowanie oparte na ocenie ryzyka jako proces projektowania, gdzie redukcja ryzyka jest traktowana jako cel projektowy, podobnie jak inne standardowe cele projektowe. W metodologii tej zastosowano podejście całościowe, łączące miary redukcji ryzyka $\mathrm{z}$ zachowaniem się statku i kosztem projektu, poprzez użycie odpowiednich narzędzi związanych z projektowaniem i eksploatacją [9][10][11]. Podejście do oceny bezpieczeństwa statków na etapie projektowania, w czasie eksploatacji i w czasie ratowania statku na morzu, które zastosowano w proponowanej przez autora metodzie, jest oparte o następujące elementy: ustalenie celów, identyfikacja zagrożeń, identyfikacja scenariuszy wypadku, ocena ryzyka, kontrola ryzyka (prewencja, redukcja) oraz wybór optymalnego projektu 
(optymalnej procedury operacyjnej), który spełnia cele bezpieczeństwa. Strukturę metody i proponowanego systemu, opartego o ocenę ryzyka, dla oceny bezpieczeństwa statków, przedstawiono na rys.1.

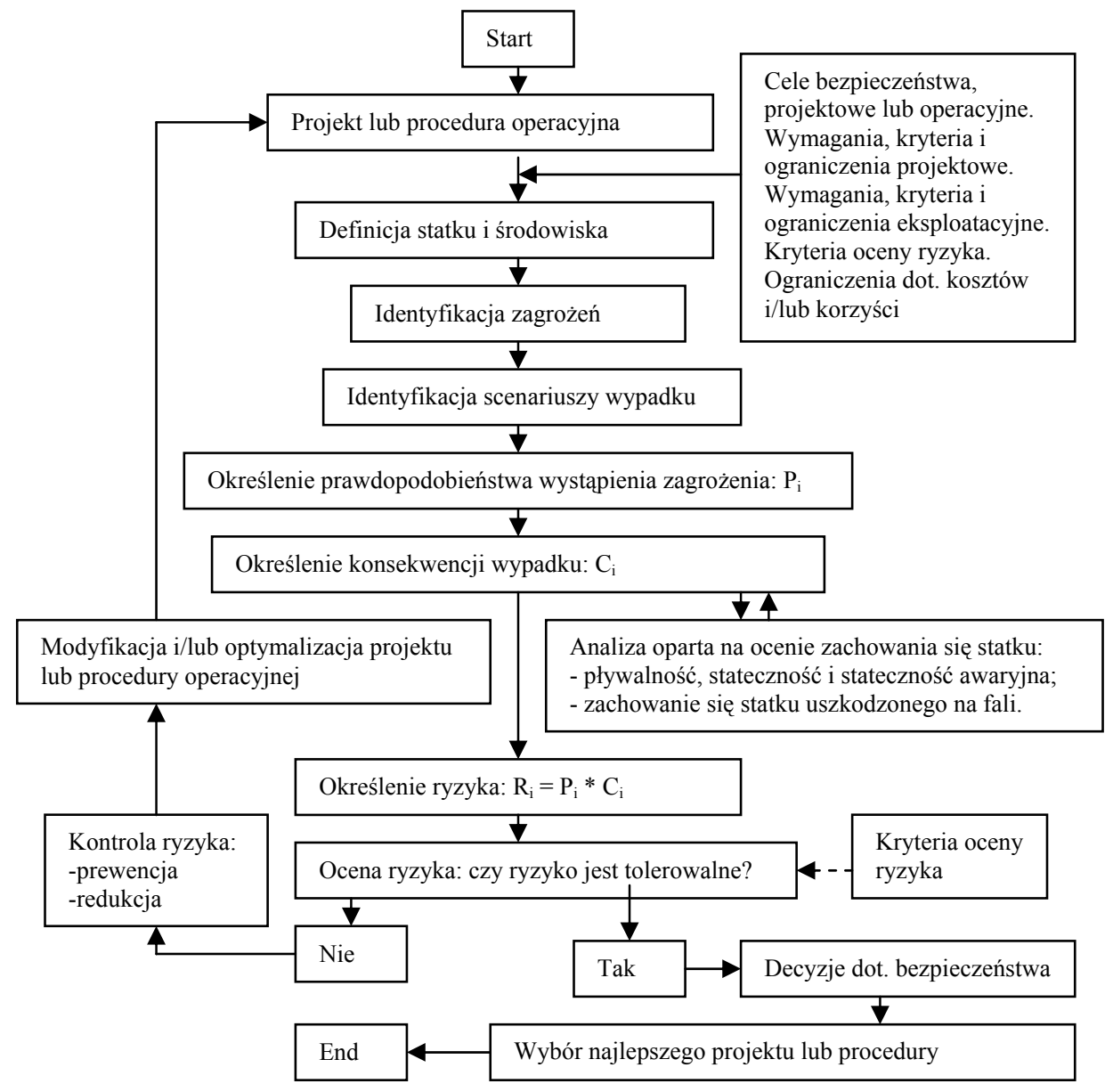

Rys. 1. Struktura sytemu projektowego (metody) opartego na ocenie ryzyka

Proponowana metoda stanowi procedurę, opartą na ocenie zachowania się statku i ocenie ryzyka, która można zastosować w projektowaniu dla bezpieczeństwa lub do oceny bezpieczeństwa transportu morskiego, w połączeniu $\mathrm{z}$ procesem redukcji ryzyka $\mathrm{i}$ zapewnienia odpowiedniego poziomu bezpieczeństwa, jego celu. Ogólnie, metodę można zastosować do oceny bezpieczeństwa statków w stanie nieuszkodzonym i uszkodzonym, ze względu na fakt, że zastosowanie metody zależne jest od definicji systemu czy problemu. Nowoczesne podejście do bezpieczeństwa statków wymaga połączenia elementów systemowego podejścia do bezpieczeństwa 
z metodologią FSA [2][3]. Do podstawowych elementów metodologii FSA można zaliczyć: identyfikację zagrożeń, ocenę ryzyka, kontrolę ryzyka, ocenę kosztów i zysków oraz decyzje dotyczące bezpieczeństwa. $\mathrm{W}$ proponowanej metodzie, powyższe elementy zostały połączone $\mathrm{z}$ procedurami projektowymi [1]. W metodzie zastosowano następujące metody identyfikacji zagrożeń, częstotliwości zdarzeń, konsekwencji i oceny ryzyka [1]: wstępna analiza zagrożeń (PHA), wstępna ocena ryzyka (PRA), analiza „co-jeśli”, analiza FMEA, analiza HAZOP, analiza FTA, analiza ETA, względny ranking, analiza CRA, analiza pareto, analiza zmian, analiza CCFA i analiza HEA [1].

\section{Modelowanie zagrożeń, konsekwencji i ryzyka}

Zasadniczym problemem związanym $\mathrm{z}$ zastosowaniem proponowanej metody jest modelowanie drzewa udziału w ryzyku, w celu dokonania oceny ryzyka. W metodzie uwzględniono trzy kategorie wypadków, które moga potencjalnie spowodować uszkodzenie poszycia kadłuba statku, a mianowicie: kolizje, uderzenia o przeszkodę i wejścia na mieliznę. Zgodnie ze statystykami wymienione kategorie wypadków stanowią główne przyczyny wypadków na morzu. Stanowią one około 53\% ogólnej liczby wypadków [6]. Drzewa udziału w ryzyku dla wymienionych kategorii wypadków zostały opracowane niezależnie, w oparciu o ogólną strukturę drzew uszkodzeń FTA i zdarzeń ETA.W metodzie zastosowano podejście oparte na funkcjonalnym drzewie zdarzeń, które może mieć charakter dynamiczny. Ogólnie, w metodzie wprowadzono szesnaście funkcji bezpieczeństwa. W metodzie zastosowano całościowe podejście do bezpieczeństwa. W związku $\mathrm{z}$ tym wprowadzono dwa założenia. Po pierwsze, uszkodzenia systemu statek mogą dotyczyć uszkodzeń statku o charakterze technicznym (hardware), związanych z właściwościami statku (software), dotyczących organizacji i zarządzania statkiem oraz uszkodzeń wynikających z działalności człowieka. Po drugie, do oceny bezpieczeństwa statków w stanie uszkodzonym należy użyć całościowego modelu ryzyka.

Ryzyko związane $z$ występowaniem różnych zagrożeń i scenariuszy wypadków należy określić zgodnie ze znanym ogólnie wyrażeniem:

$\mathrm{R}_{\mathrm{i}}=\mathrm{P}_{\mathrm{i}} \times \mathrm{C}_{\mathrm{i}}$

gdzie $\mathrm{P}_{\mathrm{i}}$ - prawdopodobieństwo wystąpienia danego zagrożenia; $\mathrm{C}_{\mathrm{i}}-$ konsekwencje wynikające $\mathrm{z}$ wystąpienia danego zagrożenia i scenariusza wypadku w formie ofiar, zranień, strat materialnych i zanieczyszczenia środowiska naturalnego. 
Całościowy model ryzyka w proponowanej metodzie ma postać następująca [1][7][9]:

$\mathrm{R}=\mathrm{P}_{\mathrm{c}} \times \mathrm{P}_{\mathrm{c} / \text { fdpe }} \times \mathrm{P}_{\mathrm{c} / \text { fdpe/ns }} \times \mathrm{P}_{\mathrm{c} / \text { fdpe/ns/ts }} \times \mathrm{C}$

gdzie $\mathrm{P}_{\mathrm{c}}-$ prawdopodobieństwo kolizji (zagrożenie); $\mathrm{P}_{\mathrm{c} / \mathrm{fdpe}} \quad-$ prawdopodobieństwo zatapiania statku na skutek zderzenia $\mathrm{z}$ innym statkiem pod danym kątem, w danym miejscu i przy danej wielkości uszkodzenia, pod warunkiem wystapienia kolizji; $\mathrm{P}_{\mathrm{c} / \text { fdpe/ns }} \quad-$ prawdopodobieństwo nie przetrwania kolizji, pod warunkiem wystapienia zatapiania statku na skutek zderzenia z innym statkiem pod danym kątem, w danym miejscu i przy danej wielkości uszkodzenia, pod warunkiem wystapienia kolizji; $\mathrm{P}_{\mathrm{c} / \mathrm{fdpe} / \mathrm{ns} / \mathrm{ts}}$ - prawdopodobieństwo zatopienia statku w danym czasie, pod warunkiem nie przetrwania kolizji, pod warunkiem wystapienia zatapiania statku na skutek zderzenia $\mathrm{z}$ innym statkiem pod danym kątem, w danym miejscu i przy danej wielkości uszkodzenia, pod warunkiem wystapienia kolizji; C - konsekwencje wypadku dotyczące ofiar, start materialnych (ładunek, statek) i/lub środowiska.

Model ryzyka można podzielić na cztery różne moduły, w zależności od charakteru strat, na model z ofiarami (HF - Human Fatalities), ze stratami dotyczącymi ładunku i statku (CS - Cargo, Ship), z zanieczyszczeniem środowiska (E - Environment) i ze stratami finansowymi (\$ - pieniądze), w sposób następujący:

$\mathrm{R}=\mathrm{P}_{\mathrm{c}} \mathrm{P}_{\mathrm{c} / \text { ddpe }} \mathrm{P}_{\mathrm{c} / \text { fdpe/ns }} \mathrm{P}_{\mathrm{c} / \text { ddpe/ns/tts }} \times \mathrm{C}_{\mathrm{HF} / \mathrm{C}}$

$\mathrm{R}=\mathrm{P}_{\mathrm{c}} \mathrm{P}_{\mathrm{c} / \text { fdpe }} \mathrm{P}_{\mathrm{c} / \text { fdpe/ns }} \mathrm{P}_{\mathrm{c} / \text { fdpe/ns/tts }} \times \mathrm{C}_{\mathrm{CS} / \mathrm{C}}$

$\mathrm{R}=\mathrm{P}_{\mathrm{c}} \mathrm{P}_{\mathrm{c} / \text { fdpe }} \mathrm{P}_{\mathrm{c} / \text { fdpe/ns }} \mathrm{P}_{\mathrm{c} / \text { /dpe/ns/tts }} \times \mathrm{C}_{\mathrm{E} / \mathrm{C}}$

$\mathrm{R}=\mathrm{P}_{\mathrm{c}} \mathrm{P}_{\mathrm{c} / \text { fdpe }} \mathrm{P}_{\mathrm{c} / \text { fdpe/ns }} \mathrm{P}_{\mathrm{c} / \mathrm{fdpe} / \mathrm{ns} / \text { tts }} \times \mathrm{C}_{\$ / \mathrm{C}}$

Ogólne wyrażenie na obliczanie prawdopodobieństwa wystapienia danych konsekwencji, biorąc pod uwagę dany scenariusz wypadku, ma postać następującą:

$\mathrm{PC}_{\mathrm{i}}=\sum_{N p r} \mathrm{P}\left(\mathrm{r}_{\mathrm{j}}\right) \mathrm{P}\left(\mathrm{C}_{\mathrm{i}}, \mathrm{r}_{\mathrm{j}}\right)$

gdzie Npr - liczba możliwych zdarzeń dla danego scenariusza wypadku; $\mathrm{P}\left(\mathrm{r}_{\mathrm{j}}\right)$ - prawdopodobieństwo wystąpienia danego zdarzenia; $\mathrm{P}\left(\mathrm{C}_{\mathrm{i}}, \mathrm{r}_{\mathrm{j}}\right)$ prawdopodobieństwo wystapienia danych konsekwencji $\mathrm{C}_{\mathrm{i}}$ pod warunkiem wystąpienia danej sekwencji zdarzeń $r_{j}$.

Do typowych zdarzeń $r_{j}$ można zaliczyć: wodę na pokładzie, poduszki powietrzne, wyciek ladunku, dodatkowe momenty przechylające, zachowanie się pasażerów. 
Model ryzyka (4) różni się od modelu opisanego przez Skjong'a et al., $\mathrm{z}$ uwagi na fakt, że $\mathrm{w}$ proponowanym modelu nie używa się prawdopodobieństwa warunkowego zatopienia statku w postaci $\mathrm{P}_{\text {sink }}=1-\mathrm{A}$, rozumianego jako prawdopodobieństwo przeciwne do wskaźnika podziału grodziowego A [9]. Przykładowe wyniki oceny zachowania się statku (kołysania boczne statku) i wyniki rozkładu ryzyka przetrwania kolizji $\left(\mathrm{R}_{\mathrm{i}}=\mathrm{P}_{\mathrm{i}} * \mathrm{C}_{\mathrm{i}}\right)$, przedstawiono na rys. 2 .
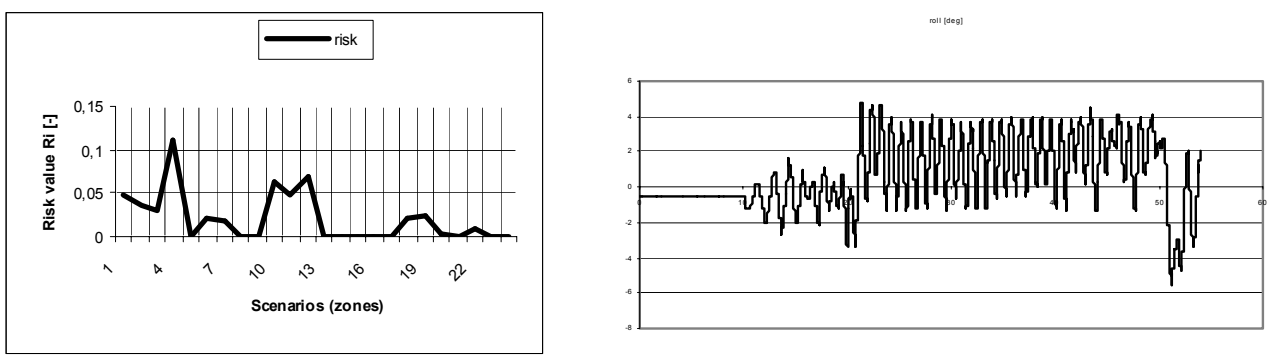

Rys. 2. Przykład oceny zachowania się statku (kołysania boczne kadłuba) i wyniki rozkładu ryzyka przetrwania kolizji $\left(\mathrm{R}_{\mathrm{i}}=\mathrm{P}_{\mathrm{i}} * \mathrm{C}_{\mathrm{i}}\right)$

\section{Wnioski}

W artykule przedstawiono krótki opis metody oceny bezpieczeństwa statków w stanie uszkodzonym, opartej na ocenie zachowania się statku i ocenie ryzyka. Obecne prace badawcze dotyczą doskonalenia i opracowywania nowych modeli ryzyka. Modele ryzyka stanowią procedury obliczeniowe, które wraz $\mathrm{z}$ oceną zachowania się statku, za pomocą badań modelowych lub przy użyciu symulacji numerycznych, wykorzystuje się do oceny bezpieczeństwa statków w stanie uszkodzonym. Trwają prace nad przystosowaniem metody do oceny bezpieczeństwa statków w stanie uszkodzonym do celów projektowych, w czasie eksploatacji oraz w przypadku prowadzenia akcji ratowniczej na morzu.

Autor chciałby wyrazić swoje podziękowania Ministerstwu Nauki i Szkolnictwa Wyższego za wsparcie badań naukowych nad nowymi rozwiqzaniami $w$ zakresie bezpieczeństwa transportu morskiego i statków.

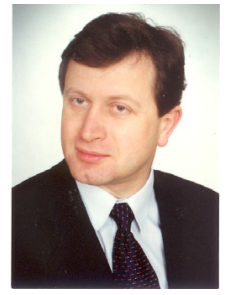

Dr.Eng. GERIGK Miroslaw, Gdansk University of Technology, Gdansk, Senior lecturer, specjalisation: ship and ocean engineering design, ship hydromechanics, ship safety, safety of sea transportation, safety of ships in damaged conditions. Over fifty publications in field. 